\title{
The Role of Weight Loss in the Management of Type 2 Diabetes
}

\author{
Marion J Franz \\ Nutrition Concepts by Franz, Inc., Minneapolis, US
}

\begin{abstract}
Weight loss is important for the prevention of prediabetes, for halting the progression of prediabetes to diabetes, and for improving metabolic outcomes early after the diagnosis of type 2 diabetes. However, as type 2 diabetes progresses from being primarily related to insulin resistance to insulin deficiency, weight loss that can be achieved by many individuals may or may not improve outcomes. A reduced energy intake continues to be essential. For some it may lead to weight loss, for some it may prevent weight regain after weight loss, and for some it may prevent weight gain, but even without weight loss, it can have beneficial effects on metabolic outcomes.
\end{abstract}

\section{Keywords}

Weight loss, type 2 diabetes, prediabetes, reduced energy intake

Disclosure: Marion J Franz has nothing to declare in relation to this article. This article is a short opinion piece and has not been submitted to external peer reviewers. No funding was received in the publication of this article.

Open Access: This article is published under the Creative Commons Attribution Noncommercial License, which permits any noncommercial use, distribution, adaptation, and reproduction provided the original author(s) and source are given appropriate credit.

Received: March 19, 2016 Published Online: April 15, 2016 Citation: US Endocrinology 2016;12(1):14-5 DOl: http://doi.org/10.17925/USE.2016.12.01.14

Correspondence: Marion J Franz, Nutrition Concepts by Franz, Inc, 6635 Limerick Drive, Minneapolis, MN 55439, US E: MarionFranz@aol.com

The increasing prevalence of overweight and obesity in the United States has been well documented, ${ }^{1}$ as have the resulting negative effects on increased risk for several chronic diseases, including type 2 diabetes. $^{2}$ Therefore, addressing overweight and obesity is an important strategy in the primary and secondary prevention of type 2 diabetes, as well as for hypertension, dyslipidemia, and cardiovascular disease. ${ }^{3}$

Strong evidence exists for the benefits of moderate weight loss for the prevention of diabetes. In persons with prediabetes, an eating plan that facilitates modest weight loss ( $5 \%$ to $7 \%$ of body weight), increases in physical activity (equivalent to 30 minutes brisk walking on most days of the week), and follow-up counseling and continued support reduced the incidence of diabetes by $58 \% .{ }^{4}$ Of importance are studies of lifestyle intervention showing persistent reduction in the rate of conversion from prediabetes to diabetes for 10 years. ${ }^{5}$ Cost data have also confirmed that lifestyle interventions for the prevention of diabetes are highly cost-effective. ${ }^{6}$

Weight-loss interventions have also been shown to be effective in improving glycemic control in persons with newly diagnosed diabetes. ${ }^{7,8}$ However, the benefit of weight loss in persons with type 2 diabetes of longer duration is controversial. ${ }^{9}$ To better understand and determine the outcomes of weight loss interventions (WLI) in overweight and obese persons with type 2 diabetes we conducted a systematic review and meta-analysis. ${ }^{10}$ The primary question being to determine the outcomes of WLI on hemoglobin $A_{1 C}\left(A_{1 c}\right)$, lipids, and blood pressure from WLIS resulting in weight losses greater than or less than $5 \%$ at 12 months and the secondary question being to determine weight and metabolic outcomes from differing amounts of macronutrients in WLI study arms.
Eleven trials with 19 WLI study arms (8 compared 2 WLIs and 3 compared a WLI to a usual care/control group) with 6,754 participants met study criteria (randomized clinical trial, minimum 12-month duration, and a 70\% completion rate). At 12 months, $17 \mathrm{WLI}$ study arms reported weight losses less than $5 \%$ (1.9 to $4.8 \mathrm{~kg}$ ), resulting in non-significant benefits on $A_{1 C^{\prime}}$ lipids, and blood pressure. Only two study arms, a Mediterranean-style diet in newly diagnosed adults and the intensive lifestyle intervention in the Action for Health in Diabetes (Look AHEAD) trial resulted in weight losses greater than $5 \%$. Both included regular physical activity by participants and frequent contact with health professionals reported significant benefits on $A_{1 C^{\prime}}$ lipids, and blood pressure. Five trials (10 study arms) compared WLIs of differing amounts of macronutrients and reported non-significant differences in weight loss, $A_{1 C^{\prime}}$ lipids, or blood pressure. Thus, a weight loss $>5 \%(\sim 6 \mathrm{~kg})$ appears necessary for beneficial outcomes from WLI in persons with type 2 diabetes. Achieving this level of weight loss requires intense interventions including energy restriction, regular physical activity, and frequent contact with health professionals.

Furthermore, it appears more difficult for persons with diabetes to lose weight than for persons without diabetes. In a systematic review of 80 weight loss studies with 26,455 participants, primarily without diabetes, at 12 months, the average weight loss was $8 \%(7.5 \mathrm{~kg})$ from baseline ${ }^{11}$ (compared with $<5 \%$ in the in the majority of studies in participants with type 2 diabetes reported above). Factors that contribute to an individual's inability to lose and maintain weight loss include low socioeconomic status, an unsupportive environment, and very importantly, physiologic changes (e.g. compensatory changes after weight loss in circulating hormones that encourage weight regain and adaptive thermogenesis). ${ }^{12-16}$ 
For overweight or obese individuals with type 2 diabetes, a weight loss of at least $5 \%$ appears necessary to consistently improve glucose, lipids, and blood pressure. This amount of weight loss may not be a realistic goal for many of the persons with type 2 diabetes seen in many healthcare settings today. However, strong evidence reports that a reduced energy intake, with or without weight loss, improves glycemic control. ${ }^{17}$ In some it may lead to weight loss, in some it may maintain weight loss, and in some (often dependent on medications used) it may prevent weight gain.
Nutrition therapy for persons with type 2 diabetes, therefore, should encourage a reduced-energy, healthy eating plan, appropriate portion sizes of food, and regular physical activity implemented by education and with continued support. It is imperative that health professionals interact collaboratively with individuals on long-term lifestyle changes they are willing and able to make. Health professionals can be of assistance, but individuals must make the final decision as to if and how they will choose appropriate portion sizes of healthy foods and participate in regular physical activity.
1. Ogden $\mathrm{CL}$, Carroll MD, Kit BK, Flegal KM, Prevalence of childhood obesity and adult obesity in the United States, 2011-2012, JAMA, 2014;249:218-38.

2. Centers for Disease Control and Prevention: Overweight and obesity: causes and consequences. Available from: http://www.cdc.gov/obesity/adult/causes/index.html. (accessed March 18, 2016)

3. Jensen MD, Ryan DH, Apovian CM, et al., 2013 AHA/ACC/TOS Guidelines for the Management of Overweight and Obesity in Adults: a report of the American College of Cardiology/ American Heart Association Task Force on Practice Guidelines and The Obesity Society, Circulation, 2014;63:2985-3023.

4. Knowler WC, Barrett-Connor E, Fowler SE, et al., Reduction in the incidence of type 2 diabetes with lifestyle intervention or metformin, N Eng J Med, 2002:346:393-403.

5. Knowler WC, Fowler SE, Hamman RF, et al., 10 year follow-up of diabetes incidence and weight loss in the Diabetes Prevention Program Outcomes Study, Lancet 2009;374: 1677-86.

6. Li R, Qu S, Zhang P, et al., Economic evaluation of combined diet and physical activity promotion programs to prevent type 2 diabetes among persons at increased risk: a systematic review for the Community Prevention Services Task Force, Ann Intern Med, 2015;163:42-460.

7. Feldstein AC, Nichols GA, Smith DH, et al., Weight changes in diabetes and glycemic and blood pressure control, Diabetes Care, 2008:31:1960-1965.

8. Esposito K, Majorino Ml, Ciotola M, et al., Effects of a Mediterranean-style diet on the need for hyperglycemic drug therapy in patients with newly diagnosed type 2 diabetes: a randomized trial, Ann Intern Med, 2009;151:306-314.

9. Franz MJ, The dilemma of weight loss in diabetes, Diabetes Spectrum, 2007;20:133-135.

10. Franz MJ, Boucher JL, Rutten-Ramos S, Van Wormer JJ, Lifestyle weight-loss intervention outcomes in overweight and obese adults with type 2 diabetes: a systematic review and meta-analysis of randomized clinical trials, I Acad Nutr Diet, 2015;115:1447-1463.

11. Franz MJ, Van Wormer JJ, Crain AL, et al. Weight loss outcomes: a systematic review and meta-analysis of weight-loss clinical trials with a minimum of 1-year duration, J Am Diet ASSOC, 2007; 107:1755-1767

12. Ochner CN, Tsai AG, Kushner RF, Wadden TA, Treating obesity seriously: when recommendtions for lifestyle change confront biological adaptations, Lancet Diabetes Endocrinol, 2015:3:232-234.

13. Ochner CN, Barrios DM, Lee CD, Pi-Sunyer FX, Biological mechanisms that promote weight regain following weight loss in obese humans, Physiol Behav, 2013;120:106-113.

14. Major GC, Doucet E, Trayhurn P, et al., Clinical significance of adaptive thermogenesis, Int J Obes, 2007;31:204-212.

15. Sumithran $P$, Prednergast $L A$, Delbridge $E$, et al., Long-term persistence of hormonal adaptations to weight loss, N Eng J Med, 2011;365:1597-1604.

16. Camps SG, Verhoef SP, Westerperp KR, Weight loss, weight maintenance, and adaptive thermogenesis, Am J Clin Nutr, 2013;97:990-994.

17. Academy of Nutrition and Dietetics. Available at: www.andevidencelibrary.com/topic.cfm? $=5305$ (accessed March 18, 2016) 